\title{
Chondroma of Tongue: A Rare Case Report \& Review of Literature
}

\author{
Anoop Attakkil, Vandana Thorawade, Mohan Jagade, Rajesh Kar, Kartik Parelkar, \\ Dnyaneswar Rohe, Poonam Khairnar, Reshma Hanowate
}

Department of ENT, Grant Medical College \& Sir J.J. Hospital, Mumbai, India

Email: fasttrack2317@gmail.com

Received 13 September 2014; revised 12 October 2014; accepted 10 November 2014

Copyright (C) 2014 by authors and Scientific Research Publishing Inc.

This work is licensed under the Creative Commons Attribution International License (CC BY). http://creativecommons.org/licenses/by/4.0/

c) (i) Open Access

\begin{abstract}
Chondromas are common benign cartilaginous tumours in the skeletal system usually found in extremities. Extra skeletal chondromas are relatively uncommon of which those in head and neck regions are rarely documented. Although the tongue is one of the most common sites of oral soft tissue chondroma, lingual chondromas are rare as evidenced by the fact that only 33 cases are identified in the review of literature till now. This report has the objective of presenting a rare case of lingual enchondroma in a 26-year-old male which was excised with no evidence of recovery during follow up. We have also tried to present a concise review of the relevant literature.
\end{abstract}

\section{Keywords}

\section{Soft Tissue Chondroma, Tongue}

\section{Introduction}

Chondromas are benign lesions of hyaline cartilage. They are common, and all age groups are affected. Chondromas usually are asymptomatic and frequently discovered incidentally during an unrelated radiographic examination. They usually arise in the medullary canal, where they are referred to as "enchondromas”. Rarely, they arise on the surface of the bone, where they are referred to as "periosteal chondromas" or "juxtacortical chondromas".

Chondromas of soft parts commonly occur in the upper and lower extremities, especially in relation to the small joints of the hand and feet [1]. Only two of Chung and Enzinger's series of 104 cases occurred in the head (1 case) and neck (1 case) [1]. Extraskeletal chondromas of the oral cavity are very rare with only 46 cases identified in review of the literature in 2011 [2]. They are found primarily in the tongue, tonsils or beneath ill-fitting dentures and only infrequently in the buccal mucosa and soft palate [1]. These tumours usually present as no symptomatic, slow-growing, and well-defined nodules, affecting both sexes equally. 
Though tongue is mentioned as the common site, a case of chondroma of tongue gains significance when we consider the fact that only 33 cases are reported in world literature [2]. In this paper we report a case of soft tissue chondroma arising from tongue and present a review of the literature.

\section{Case Report}

A 26-year-old policeman presented with complaints of mass over posterior part of tongue noticed since 15 years which was insidious in onset and gradually progressive. It was not associated with pain, dysphagia or odynophagia. The patient had no history of any significant medical or surgical illnesses in the past. He gave no history of addictions. Oral cavity examination revealed a smooth surfaced, pedunculated, swelling of size $2 \times 1 \times 1 \mathrm{~cm}$ slightly lateral to midline on the ventral surface, arising from junction of anterior two third \& posterior one third of the tongue. It was non tender, hard in consistency, non pulsatile with dilated blood vessels seen over the same (Figure 1).

On MRI of tongue, one well defined exophytic polypoidal mass lesion measuring $2.2 \times 1.6 \times 1.3 \mathrm{~cm}$ was seen arising from the tongue at the junction of anterior two third \& posterior one third. It showed hyperintense with hypointense foci on stir and heterogenous on $\mathrm{t} 1 \mathrm{w}$ and $\mathrm{t} 2 \mathrm{w}$ images. There was no post contrast enhancement noticed. No deep extension or involvement of extrinsic or intrinsic muscles was present (Figure 2).

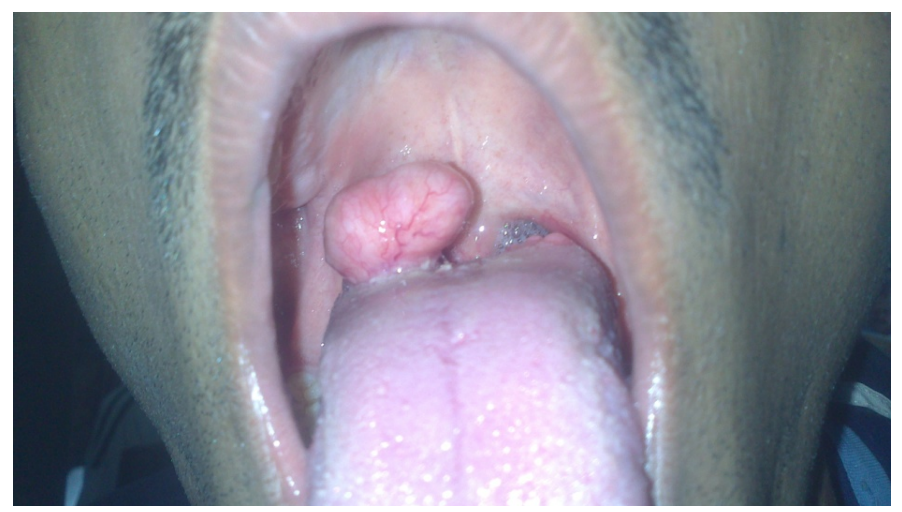

Figure 1. Chondroma on the tongue lying just lateral to midline.

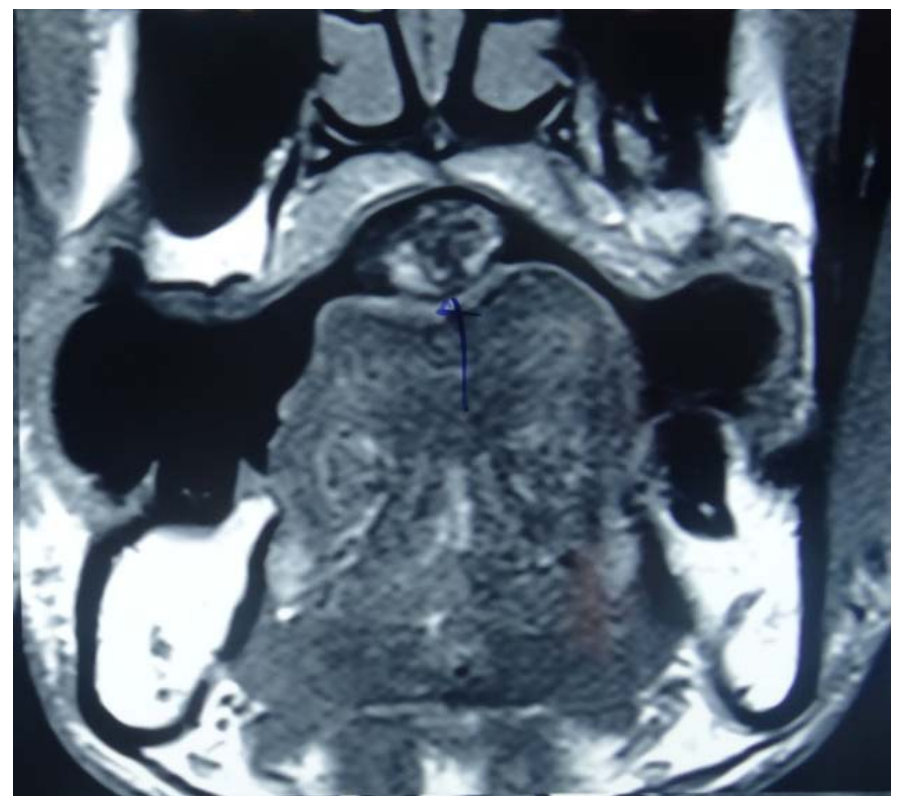

Figure 2. MRI of tongue showing the pedunculated lesion over tongue. 
Under general anaesthesia, wide local excision of the tumour along with tongue tissue keeping $1 \mathrm{~cm}$ margin was done. Haemostasis was achieved with bipolar cauterisation and the specimen was sent for histopathological examination (Figure 3).

Histopathological examination showed the tumour was multinodular and greyish with slightly well-defined edges. Microscopic examination revealed, multiple nodules composed of spindle cells surrounded by inflammatory round cells and fibrosis. Some showed cartilaginous formation by chondrocytes confirming the diagnosis of chondroma (Figure 4).

Postoperative period was uneventful. Patient was followed up for 1 year with no evidence of recurrence.

\section{Discussion}

Tumours of the oral cavity and oropharynx may be either epithelial, mesenchymal, or haematolymphoid of which soft tissue chondromas are very rare. Soft tissue chondromas are usually diagnosed within the extremities, the fingers being frequently affected [3] [4]. Other sites reported include the dura, larynx, skin, and fallopian tube [3] [5]-[8].

Soft tissue chondromas of the oral cavity are rare; only 46 cases have been reported in the English literature [2]. The tongue was the most common site (33 of 46), followed by buccal mucosa (4 of 46), hard palate (4 of
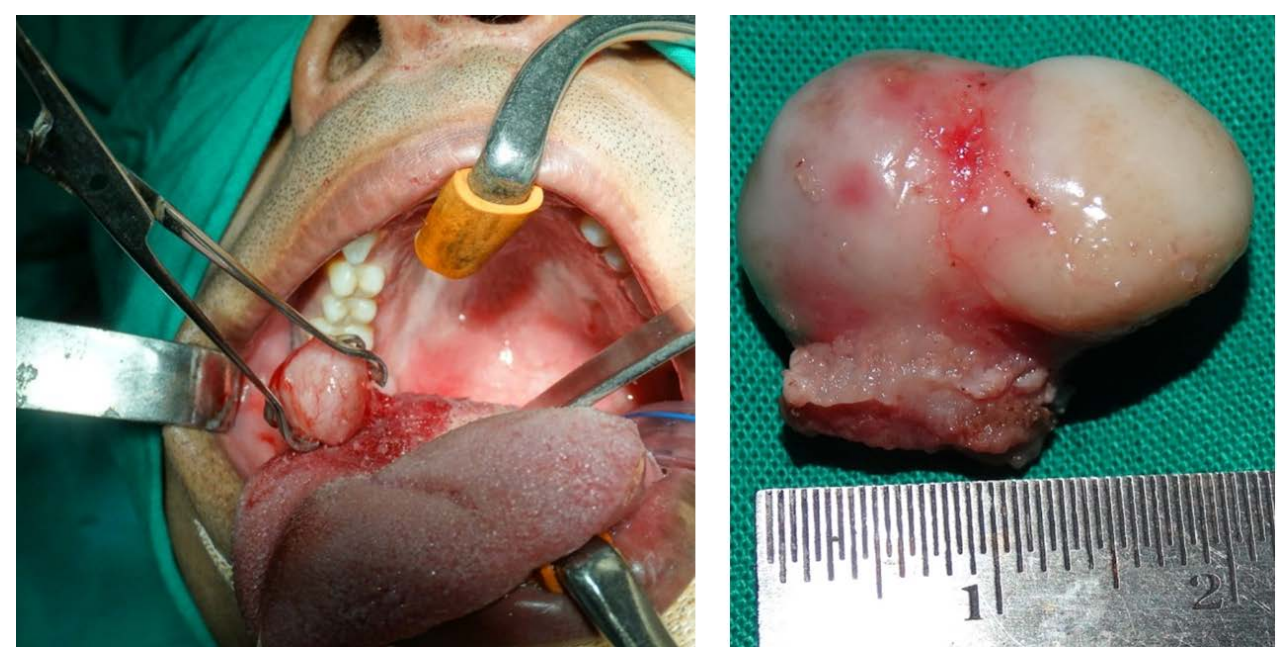

Figure 3. Intraoperative and post operative photographs showing the excision of $2 \times 1 \times 1 \mathrm{~cm}$ mass.

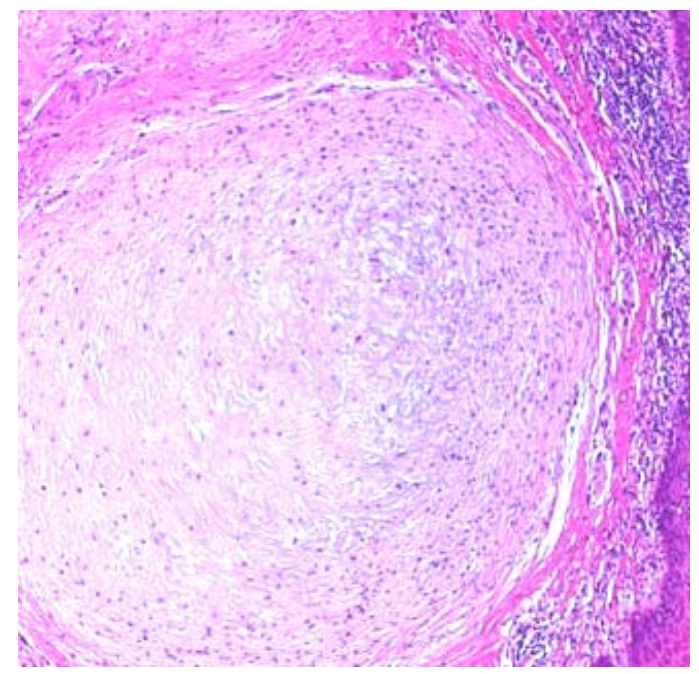

Figure 4. Microscopic appearance of the tumor (hematoxylin \& eosin stain, 50× magnification). 
46), gingiva (3 of 46), soft palate (1 of 46), and lip (1 of 46) [2]. Usually common in the middle age population with a slight higher incidence in females [2]. There are varied school of thoughts regarding the origin of chondromas in oral cavity. The "embryonic remnants theory" suggests that heterotopic cartilage remnants from the branchial arches get displaced during the development and get sequestered in the tongue [9] [10] which explains the increased incidence of the same in the tongue.

The "metaplastic theory" explains the lesions located on the lateral border, ventral surface or tip of the tongue, especially in an older age group more attractively. It suggests the factors like trauma, chronic irritation can stimulate metaplasia and subsequent development of tumours [11]-[15].

The high incidence of the recently described ectomesenchymal chondromyxoid tumours at the tongue may be explained by a possible pathogenetic mechanism involving the paraphysiologic cartilaginous tissue of the lingual septum (so-called "knorpelinsel") [16]. This theory may be used to explain the chondrosarcomas of the tongue also [17].

The origin of cartilage in our case is more in support of embryonic theory when we consider the presence of swelling from childhood and the site of tumour on the ventral surface of the tongue lateral to midline. Further there is no history of trauma or use of dentures in this case.

STCs are composed of lobules of mature, adult hyaline cartilage, with chondrocytic cells often growing in clusters [3] with a less incidence of calcification in the centre. Differential diagnosis include pleomorphic adenoma, tumours with primary cartilaginous differentiation (e.g., ectomesenchymal chondromyxoid tumour; extra skeletal myxoid and mesenchymal chondrosarcoma) or as a secondary metaplastic process (e.g., malignant nerve sheath tumours, oral malignant melanoma) [3] [16] [18]. Diagnosis is only confirmed after histopathological evaluation.

These tumours are usually benign with very low recurrence rate [3]. As evidenced in the literature, our patient underwent surgical excision and is on follow up with no evidence o recurrence.

\section{Conclusion}

To conclude, our case report presents one of the rare tumours of the tongue reported ever in the literature with a literature review and emphasizes on the proper histopathological evaluation of the tumours in head and neck region despite the benign nature.

\section{References}

[1] Barnes, L. (2000) Surgical Pathology of the Head and Neck. 2nd Edition, Vol. 2, CRC Press, Boca Raton, 953.

[2] Kawanoa, T., Yanamotoa, S., Kawasakia, G., Mizunoa, A., Fujita, S. and Ikedab, T. (2011) Soft Tissue Chondroma of the Hard Palate: A Case Report. Asian Journal of Oral and Maxillofacial Surgery, 23, 92-95. http://dx.doi.org/10.1016/j.ajoms.2011.01.002

[3] Nayler, S. and Heim, S. (2002) Soft Tissue Condroma. Tumors of Soft Tissue and Bone. In: Fletcher, D.M., Unni, K.K. and Mertens, F., Eds., WHO Classification of Tumours (Chondro-Osseous Tumours), WHO, Lyon, 180-181.

[4] Dahlin, D.C. and Salvador, A.H. (1974) Cartilaginous Tumors of the Soft Tissues of the Hands and Feet. Mayo Clinic Proceedings, 49, 721-726.

[5] Brownlee, R.D., Sevick, R.J., Rewcastle, N.B. and Tranmer, B.I. (1997) Radiologic-Pathologic Correlation. Intracranial Chondroma. The American Journal of Neuroradiology, 18, 889-893.

[6] Devaney, K.O., Ferlito, A. and Silver, C.E. (1995) Cartilaginous Tumors of the Larynx. Annals of Otology, Rhinology and Laryngology, 104, 251-255. http://dx.doi.org/10.1177/000348949510400313

[7] Ando, K., Goto, Y., Hirabayashi, N., Matsumoto, Y. and Ohashi, M. (1995) Cutaneous Cartilaginous Tumor. Dermatologic Surgery, 21, 339-341. http://dx.doi.org/10.1111/j.1524-4725.1995.tb00186.X

[8] Han, J.Y., Han, H.S., Kim, Y.B., Kim, J.M. and Chu, Y.C. (2002) Extraskeletal Chondroma of the Fallopian Tube. Journal of Korean Medical Science, 17, 276-278. http://dx.doi.org/10.3346/jkms.2002.17.2.276

[9] Weitzner, S., Stimson, P.G. and McClendon, J.L. (1987) Cartilaginous Choristoma of the Tongue. Journal of Oral and Maxillofacial Surgery, 45, 185-187. http://dx.doi.org/10.1016/0278-2391(87)90412-5

[10] Moore, K., Worthington, P. and Campbell, R.L. (1990) Firm Mass of the Tongue. Journal of Oral and Maxillofacial Surgery, 48, 1206-1210. http://dx.doi.org/10.1016/0278-2391(90)90539-E

[11] Toida, M., Sugiyama, T. and Kato, Y. (2003) Cartilaginous Choristoma of the Tongue. Journal of Oral and Maxillofacial Surgery, 61, 393-396. http://dx.doi.org/10.1053/joms.2003.50065 
[12] Cutright, D.E. (1972) Osseous and Chondromatous Metaplasia Caused by Dentures. Oral Surgery, Oral Medicine, Oral Pathology and Oral Radiology, 34, 625-633. http://dx.doi.org/10.1016/0030-4220(72)90346-5

[13] Magnusson, B.C., Engstrom, H. and Kahnberg, K.E. (1986) Metaplastic Formation of Bone and Chondroid in Flabby Ridges. British Journal of Oral and Maxillofacial Surgery, 24, 300-305. http://dx.doi.org/10.1016/0266-4356(86)90097-5

[14] Takeda, Y. (1987) Cartilaginous Metapalasia of the Human Aponeurosis Linguae: Histologic and Ultrasutructural Study. Journal of Oral Medicine, 42, 35-37.

[15] Lloyd, S., Lloyd, J. and Dhillon, R. (2001) Chondroid Metaplasia in a Fibroepithelial Polyp of the Tongue. Journal of Laryngology \& Otology, 115, 681-682. http://dx.doi.org/10.1258/0022215011908630

[16] de Visscher, J.G.A.M., Kibbelaar, R.E. and van der Waal, I. (2003) Ectomesenchymal Chondromyxoid Tumor of the Anterior Tongue. Report of Two Cases. Oral Oncology, 39, 83-86. http://dx.doi.org/10.1016/S1368-8375(01)00117-8

[17] Roy, J.J., Klein, H.Z. and Tipton, D.L. (1970) Osteochondroma of the Tongue. Archives of Pathology, 89, 565-568.

[18] Rosemberg, A.E. and Heim, S. (2002) Extraskeletal Osteosarcoma. Tumors of Soft Tissue and Bone. In: Fletcher, D.M., Unni, K.K. and Mertens, F., Eds., WHO Classification of Tumors (Chondro-Osseous Tumours), WHO, Lyon, 182-183. 
Scientific Research Publishing (SCIRP) is one of the largest Open Access journal publishers. It is currently publishing more than 200 open access, online, peer-reviewed journals covering a wide range of academic disciplines. SCIRP serves the worldwide academic communities and contributes to the progress and application of science with its publication.

Other selected journals from SCIRP are listed as below. Submit your manuscript to us via either submit@scirp.org or Online Submission Portal.
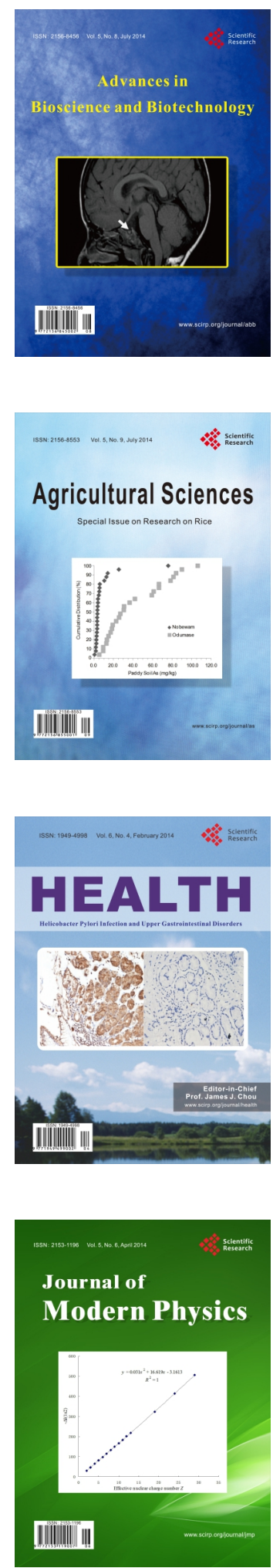
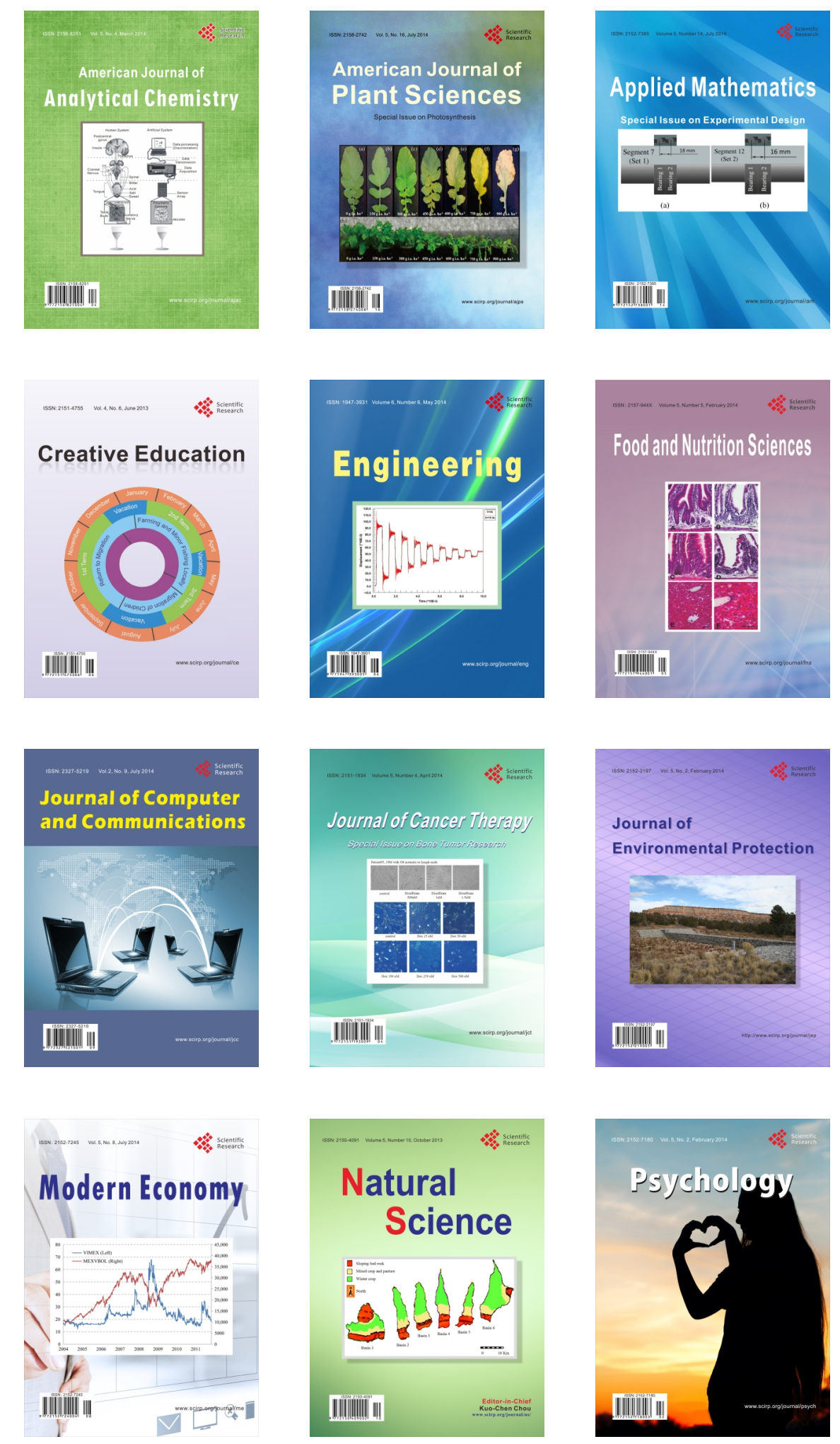